\title{
Synthesis and characterization of ceramic nanoparticles reinforced lead-free solder
}

\author{
Zahra Fathian $^{1}$, Ali Maleki ${ }^{2 *}$, Behzad Niroumand ${ }^{1}$ \\ 1- Department of Materials Engineering, Isfahan University of Technology, Isfahan, 84156-83111, Iran \\ 2- Research Institute for Steel, Isfahan University of Technology, Isfahan, 84156-83111, Iran \\ *Corresponding author: maleki110@cc.iut.ac.ir
}

\begin{abstract}
$\mathrm{Sn}-0.7 \mathrm{Cu}$ is among the least expensive types of lead-free solders available. However, its poor mechanical properties have limited its application. In this study, $\mathrm{Sn}-\mathrm{Cu}$ lead-free solder reinforced with amorphous silica $\left(\mathrm{SiO}_{2}\right)$ nanoparticles was synthesized through powder metallurgy route. Desired mixtures of raw materials was mechanically milled, compressed, sintered and extruded to prepare bulk solder samples. The samples were characterized by optical and electron microscopy as well as mechanical tests. The results showed that mechanical properties were increased by addition of $\mathrm{SiO}_{2}$ nanoparticles to the solder matrix. Addition of $1.5 \mathrm{wt} . \%$ ceramic reinforcement to the composite increased tensile, yield and compressive strengths up to 27, 23 and 41 percent, respectively, compared to those of the monolithic sample. In addition, the ceramic nanoparticles caused an up to 50\% decrease in the wetting angle between the substrate and the nanocomposite solder.
\end{abstract}

Keywords: lead-free solder, nanocomposite, $\mathrm{Sn}-\mathrm{Cu}, \mathrm{SiO}_{2}$, mechanical properties, microstructure, wettability 


\section{Introduction}

Soldering processes have been widely used in all electronic products since the beginning of the electronics era. Majority of solder materials used are traditionally based on $\mathrm{Sn}-\mathrm{Pb}$ alloys. In recent decades, due to hazards of lead toxicity for humans and its environmental impacts, application of Sn-Pb solders has been prohibited. $\mathrm{Sn}-\mathrm{Cu}$ [1-3], Sn-Ag [1-4] and Sn-Ag-Cu(SAC) $[5,6]$ have been the three pioneer lead-free solder systems [1, 7] to replace $\mathrm{Sn}-\mathrm{Pb}$. Eutectic $\mathrm{Sn}$ $\mathrm{Cu}$ alloy, i.e. $\mathrm{Sn}-0.7 \mathrm{Cu}$ has good wettability, with creep and fatigue behavior better than $\mathrm{Sn}-\mathrm{Pb}$ alloys. In addition, it is much cheaper than other lead-free solders, but its tensile strength is lower than $\mathrm{Sn}-\mathrm{Pb}$ and $\mathrm{Sn}-\mathrm{Ag}-\mathrm{Cu}$ solders [7-9].

One of the solutions proposed to improve solder mechanical properties, is refinement of microstructure which also improves other properties. This can be implemented by adding ceramic micro and nanoparticles to lead-free solder alloys. The latter results in nanocomposite solders.

The goal of manufacturing a stable composite is to achieve a fine-grained microstructure which improves plastic deformation resistance of the solder. The added reinforcing particles provide high stability of the microstructure and mechanical properties while change of melting temperature and solder wettability is negligible. The microstructure of composites is also improved by decreasing the average size and the distance between intermetallic compounds [1013]. Microstructure of $\mathrm{Sn}-\mathrm{Cu}$ solders consists of $\beta \mathrm{Sn}$, eutectic $\mathrm{Sn}-\mathrm{Cu}$ and $\mathrm{Cu}_{6} \mathrm{Sn}_{5}$ intermetallic compounds.

Zhang and $\mathrm{Tu}$ [14] showed that by adding micro and nanoparticles, distribution of $\mathrm{Cu}_{6} \mathrm{Sn}_{5}$ intermetallic compound in the matrix of $\beta \mathrm{Sn}$ and consequently mechanical properties could be changed. As an example for micro particles, $\mathrm{Si}_{3} \mathrm{~N}_{4}$ can affect microstructure of lead-free $\mathrm{Sn}-\mathrm{Cu}$ solder. The particles postpone grain growth by accumulation at the grain boundaries. In addition, heterogeneous nucleation can be increased resulting in reduced size of $\mathrm{Cu}_{6} \mathrm{Sn}_{5}$ and $\beta \mathrm{Sn}$ phases. Experiments suggests that adding $0.5 \% \mathrm{Si}_{3} \mathrm{~N}_{4}$ to a matrix of $\mathrm{Sn}-0.7 \mathrm{Cu}$ lead-free solder results in higher mechanical properties compared to SAC. It also increases thermal conductivity of Sn$0.7 \mathrm{Cu}[14]$.

In the case of nanoparticles, they could be either metallic or ceramic materials. For instance, to change the microstructure, silver (Ag) nanoparticles were added to eutectic $\mathrm{Sn}-\mathrm{Cu}$ solder. Silver 
nanoparticles were found not only inside grains but also in the grain boundaries. If excessive nanoparticles were added, silver micro-particles could also be found in molten solder due to the agglomeration of nanoparticles. After a period of service, Ag and Sn atoms can diffuse, react and form $\mathrm{Ag}_{3} \mathrm{Sn}$ intermetallic compound which can deteriorate microstructure of the $\mathrm{Sn}-\mathrm{Cu}$ lead-free solder [14].

Tsao et al. [12] reported the effect of $\mathrm{TiO}_{2}$ nanoparticles on microstructure of cast $\mathrm{Sn}-0.7 \mathrm{Cu}$ nanocomposite solders. Addition of a small amount of $\mathrm{TiO}_{2}$ nanoparticles to $\mathrm{Sn}-\mathrm{Cu}$ solder, refined its microstructure. Indeed as $\mathrm{TiO}_{2}$ nanoparticles content increased, both $\mathrm{Cu}_{6} \mathrm{Sn}_{5}$ and $\beta \mathrm{Sn}$ phase became finer, whereas number of $\mathrm{Cu}_{6} \mathrm{Sn}_{5}$ particles increased and they were distributed more uniformly in the eutectic phase. Zhang and Gupta [9] added 0.25 to 1.5 percent of $\mathrm{Al}_{2} \mathrm{O}_{3}$ nanoparticles to synthesize $\mathrm{Sn}-0.7 \mathrm{Cu}$ matrix composite through powder metallurgy. The nano $\mathrm{Al}_{2} \mathrm{O}_{3}$ increased micro-hardness, hardness and yield strength. Tensile strength of $\mathrm{Sn}-0.7 \mathrm{Cu}-$ $0.25 \mathrm{Al}_{2} \mathrm{O}_{3}$ nanocomposite was equal to $\mathrm{Sn}-\mathrm{Pb}$ solder. This amount of nano $\mathrm{Al}_{2} \mathrm{O}_{3}$ has no effect on the characteristics of the grains and the second phase, while increasing ceramic nanoparticle content leads to a greater number of cavities, as well as change of their size and disorder.

Shi et al. [13] investigated the effects of particle size on mechanical properties of composite solders. They added tin and copper micro and nanoparticles to $\mathrm{Sn}-\mathrm{Cu}$ and $\mathrm{Sn}-\mathrm{Pb}$ solders and investigated their creep behavior. Their results indicated that nanoparticles reinforced alloy may have higher shear strength than micro-particles reinforced alloy, however, micro-particles improve creep behavior better than nanoparticles. They believed this was due to the ability of nanoparticles to refine the matrix grains which in turn decreased the creep resistance.

There are several routes to synthesize composite solders which are mainly in two categories, i.e. powder metallurgy and melt metallurgy. Powder Metallurgy is more accurate and cost benefit. It can be used to incorporate reinforcement of different shapes and sizes in the desired matrix [15, 16].

There are few studies on the effect of ceramic nanoparticles on properties of $\mathrm{Sn}$-Cu lead-free solder. To the best of authors' knowledge, no research has been published which investigated the effect of amorphous nanosilica $\left(\mathrm{SiO}_{2(\mathrm{np})}\right)$ on properties of eutectic $\mathrm{Cu}-\mathrm{Sn}$ solder. Therefore, in this research, synthesis and characterization of $\mathrm{Sn}-\mathrm{Cu}-\mathrm{SiO}_{2(\mathrm{np})}$ lead-free nanocomposite solder is reported. The nanocomposite was prepared through powder metallurgy. Up to $2 \mathrm{wt} \%$ of the 
reinforcement was added to the solder and its effects on properties such as tensile and compressive strength, hardness, microstructure and wetting angle were investigated.

\section{Experimental procedure}

The lead-free solder raw materials were pure tin powder $(<63 \mu \mathrm{m},>99 \%$ purity, Mahoor Co., Iran) and pure copper powder $(<20 \mu \mathrm{m},>99 \%$ purity, Merck, Germany). Ceramic reinforcement powder (nanosilica) was prepared according to the procedure reported by Senemar et al. [17] where nanoparticles were synthesized by pyrolysis of a Silicone polymer at $700^{\circ} \mathrm{C}$. Fig. 1 shows micrographs of the raw materials.
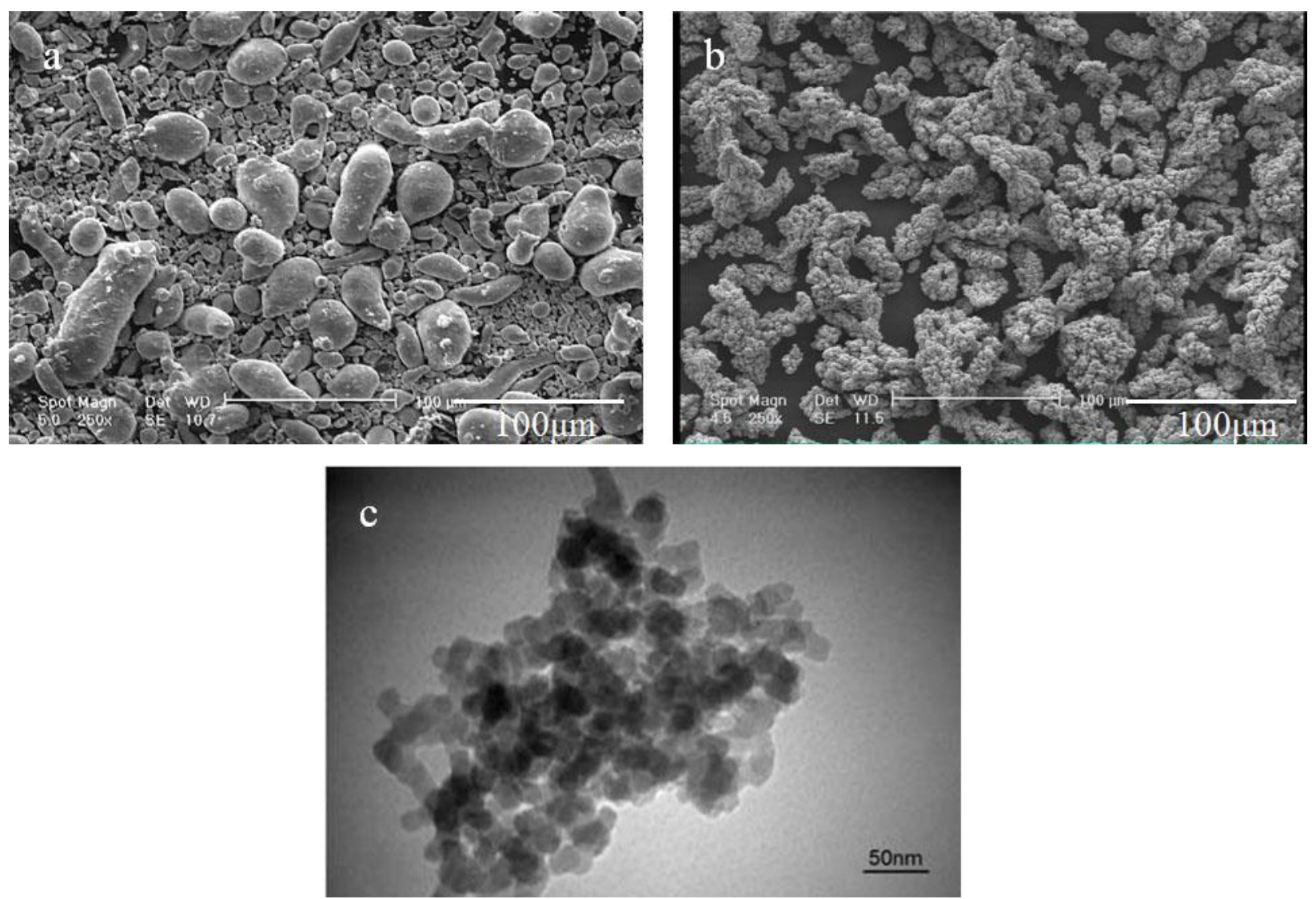

Figure 1. Micrographs of a) tin powder, b) copper powder and c) $\mathrm{SiO}_{2}$ nanoparticles [17] used in this study.

Five samples of Sn-0.7Cu containing $0,0.5,1,1.5$ and 2 weight percent of silica were prepared for later processing. The correct mixture of raw materials for each sample was milled for one 
hour in a planetary ball mill under argon atmosphere using wear resistant steel balls and vial with a ball to powder ratio of 5 . Rotation speed was $200 \mathrm{rpm}$ for all samples and no PCA was employed.

The ball milled samples (Fig. 2a) were then compacted under $200 \mathrm{MPa}$ pressure in a cylindrical die of $20 \mathrm{~mm}$ inner diameter at ambient temperature. Zinc stearate was used as lubricating agent in the compaction die to facilitate densification and ejection of the compacted samples. These samples were then sintered in a tube furnace at $180^{\circ} \mathrm{C}$ for 2 hours under argon atmosphere (Fig. $2 b$ ). Finally the sintered samples were extruded to a rod of $0.7 \mathrm{~mm}$ diameter at ambient temperature (Fig. 2c). A mixture of graphite and grease was used as extrusion lubricator.

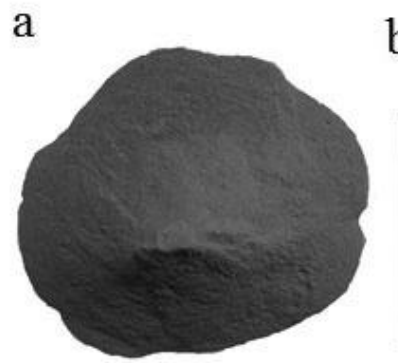

$\mathrm{b}$

c
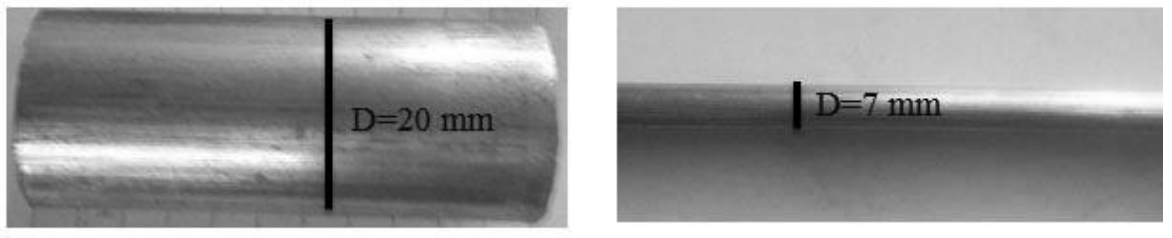

Figure 2. a) Ball milled Sn-0.7Cu containing nanoparticles, b) compacted and sintered and c) extruded samples.

To investigate the effect of ball milling, a non-ball milled mixture of $\mathrm{Sn}-0.7 \mathrm{Cu}$ and $1 \mathrm{wt} \% \mathrm{SiO}_{2(\mathrm{np})}$ powders prepared by rotational mixing, was compacted, sintered and extruded similarly. The effect of extrusion temperature was investigated by extruding $1 \%$ nanoparticle reinforced samples at ambient temperature and $200^{\circ} \mathrm{C}$.

Microstructure of the samples in non-etched and etched conditions were studied using light microscope (Nicon Epiphot300), scanning electron microscope (SEM-Philips XL Series) equipped with energy dispersive spectroscopy (EDS) and field emission SEM (MIRA3TESCAN-XMU). The etchant was a solution containing 5\% nitric acid and 95\% ethanol similar to [12]. Grain size measurements were done using MIP image analysis software [18].

Wettability tests were performed to assess the wetting angle of the solders with copper substrates. Polished discs of $250 \mathrm{mg}$ weight of the extruded rods were put on a copper substrate. To attain a better contact, substrate surface were first grinded to remove any pollution and 
soldering grease (Lotfett Co.) was applied on it. Then the disc and substrate were held for 4 minutes at $300^{\circ} \mathrm{C}$ in a resistant furnace and then cooled to room temperature. Afterwards a contact angle measurement setup was used to determine the contact angle between the lead-free solders and the substrate.

Mechanical properties of composite lead-free solders were also evaluated. Microhardness of extruded and polished samples was measured according to the ASTM E384-99 standard [19] using $25 \mathrm{~g}$ indenting load. Tensile properties of extruded sample was evaluated according to the ASTM E8M-01 standard [20]. Tensile test was performed on the samples at room temperature with Hounsfield $\mathrm{H} 25 \mathrm{~K}$ machine at strain rate of $2.08 \times 10^{-4} \mathrm{~S}^{-1}$. Compression test was conducted using the same machine on samples with $\mathrm{H} / \mathrm{D}=1.2$ at strain rate of $8 \times 10^{-4} \mathrm{~S}^{-1}$ according to ASTM E9-09 standard [21]. Dimensions of tensile and compression test specimens are shown schematically in Fig. 3. Tension and compression test for each sample was performed on three specimens and the average was reported. The \pm indicates the variation range of the results.

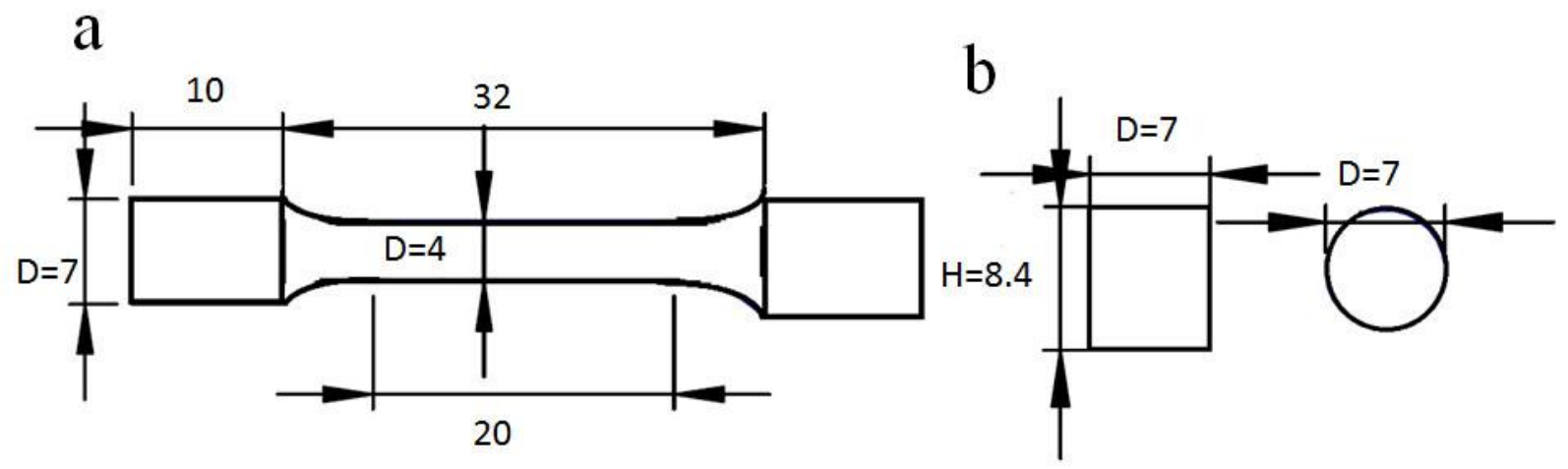

Figure 3. Dimensions of a) tensile and b) compression test specimens.

\section{Results and discussion}

\subsection{Effect of ball milling}

Fig 4. shows powders of $\mathrm{Sn}-0.7 \mathrm{Cu}$ samples containing one percent silica nanoparticles. As can be seen in the micrograph of powders mixture (Fig. 4a), metallic particles and ceramic nanoparticles has no interaction. Fig. $4 \mathrm{~b}$ is micrograph of the powders mixture after ball milling for one hour. It reveals that after this period of ball milling, nanoparticles are distributed in the metallic powder particles and cannot be seen individually. Figs. 4c and $4 \mathrm{~d}$ indicate ball milled 
$\mathrm{Sn}-0.7 \mathrm{Cu}-1 \mathrm{wt} \% \quad \mathrm{SiO}_{2}$ powder at higher magnifications which confirm incorporation of nanoparticles in to metallic particles and formation of nanocomposite powder.
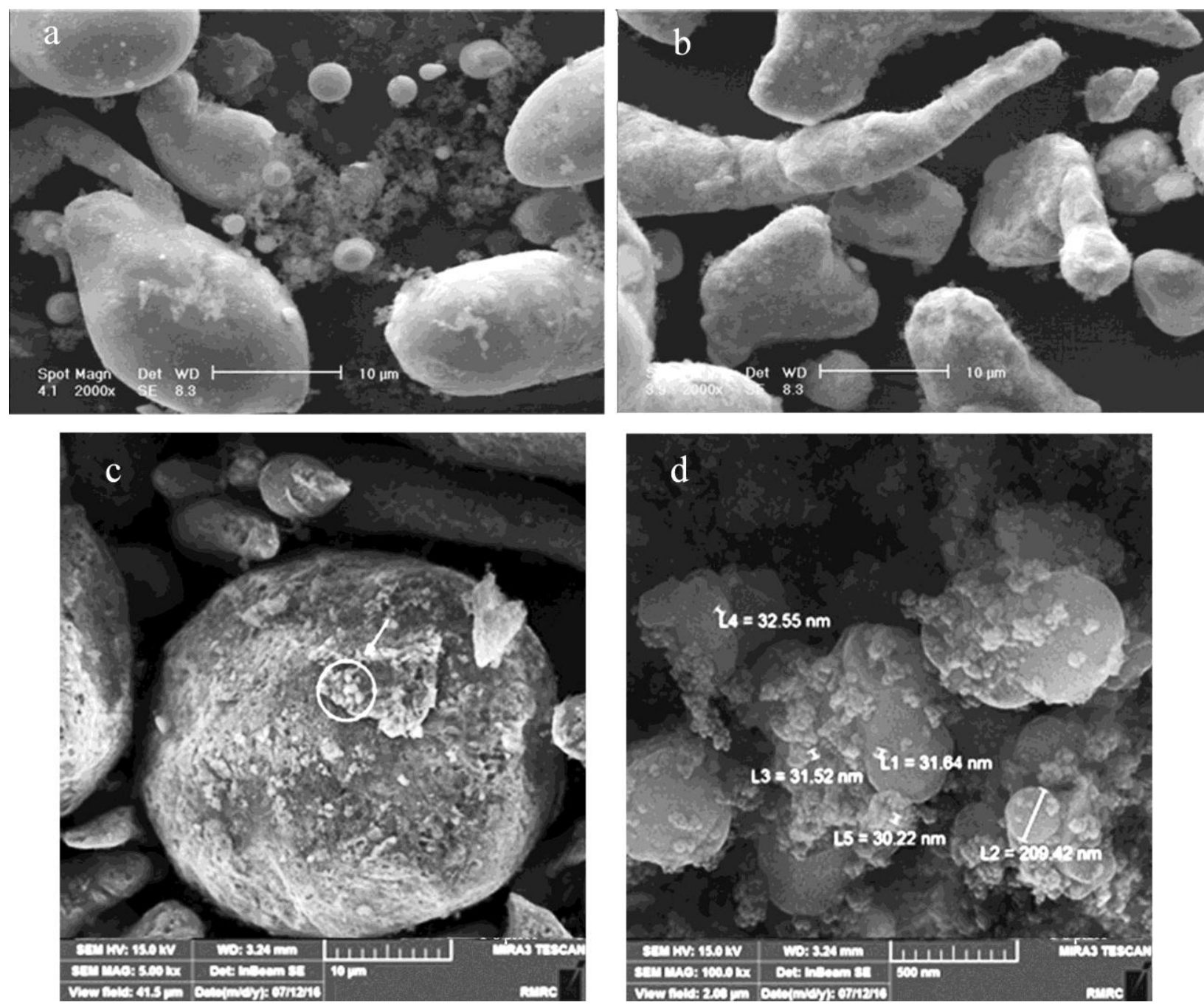

Figure 4. Scanning electron microscopy of $\mathrm{Sn}-0.7 \mathrm{Cu}-1 \mathrm{wt} \% \mathrm{SiO}_{2(\mathrm{np})}$ : a) mixture and b-d) ball milled at different magnifications.

Usually nanoparticles have high specific area which is more than $200 \mathrm{~m}^{2} / \mathrm{g}$ for amorphous nanosilica particles used in this study [17]. When ceramic nanoparticles are mixed with a metallic powder, they can cover surface of metal particles (Fig. 5a) and prevent appropriate contact of metal particles. Ball milling causes indentation of nanoparticles into metal particles (Fig. 5b). Therefore nanoparticles distribution in the matrix becomes more uniform, which is desired for metal matrix composites. Moreover in this condition, enough metallic surface of 
particles is available which helps better particle connection and material consolidation in later processing stages.
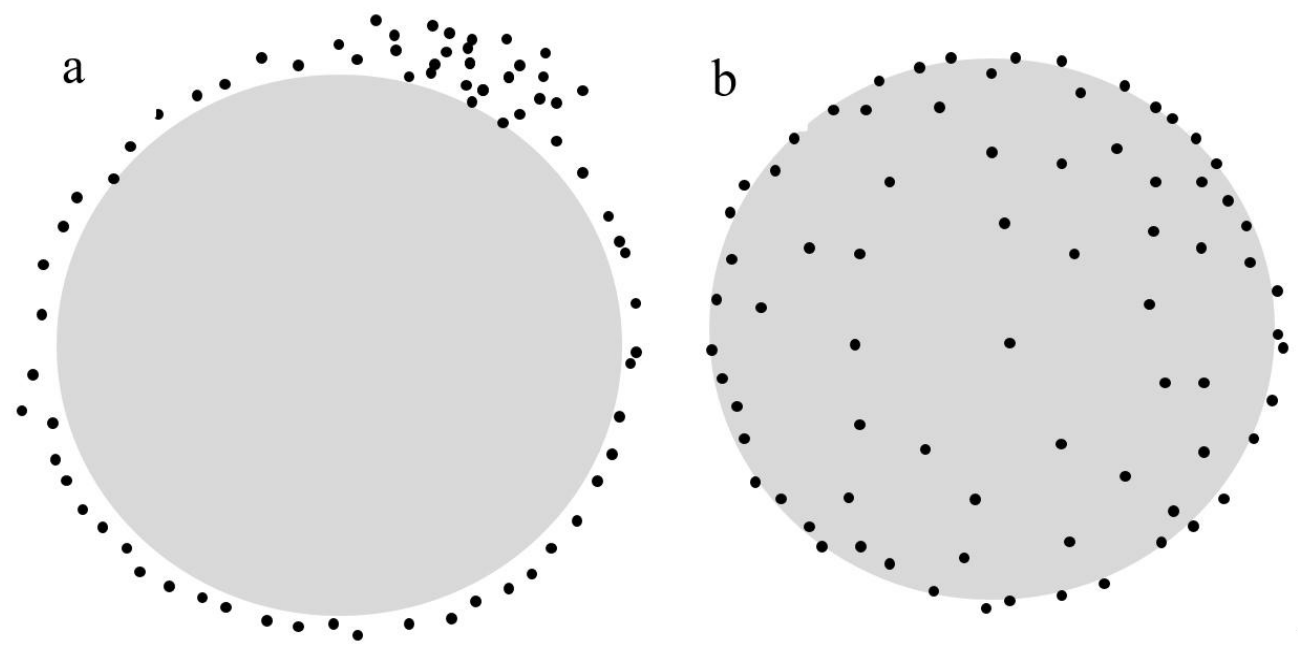

Figure5. Schematic representation of nanoparticles and metal powder: a) mixture and b) ball milled.

\subsection{Effect of extrusion temperature}

Extrusion was carried out at room temperature and $200^{\circ} \mathrm{C}$, to investigate the effect of temperature. Fig. $6 \mathrm{a}$ and $6 \mathrm{~b}$ indicates monolithic and composite samples extruded at room temperature. Figs. $6 \mathrm{c}$ and $6 \mathrm{~d}$ indicate monolithic and composite samples extruded at $200^{\circ} \mathrm{C}$. As can be seen, extrusion of lead free solder at room temperature results a defect-free appearance while the samples extruded at $200^{\circ} \mathrm{C}$ have lots of cracks which are more severe in the composite sample. In fact, in hot extrusion because of high temperature, there is more friction between mold and sample. Indeed as temperature increases, sticking of the sample to the mold as well as coefficient of friction increase. This increases friction which induces a force opposite to sample movement direction which causes radial cracks in the rod [22]. The cracks have occurred more frequently in hot extrusion of composite samples which seems to be because of higher friction between the composite and mold. Therefore room temperature was selected as the more appropriate temperature for extrusion of sintered samples. 

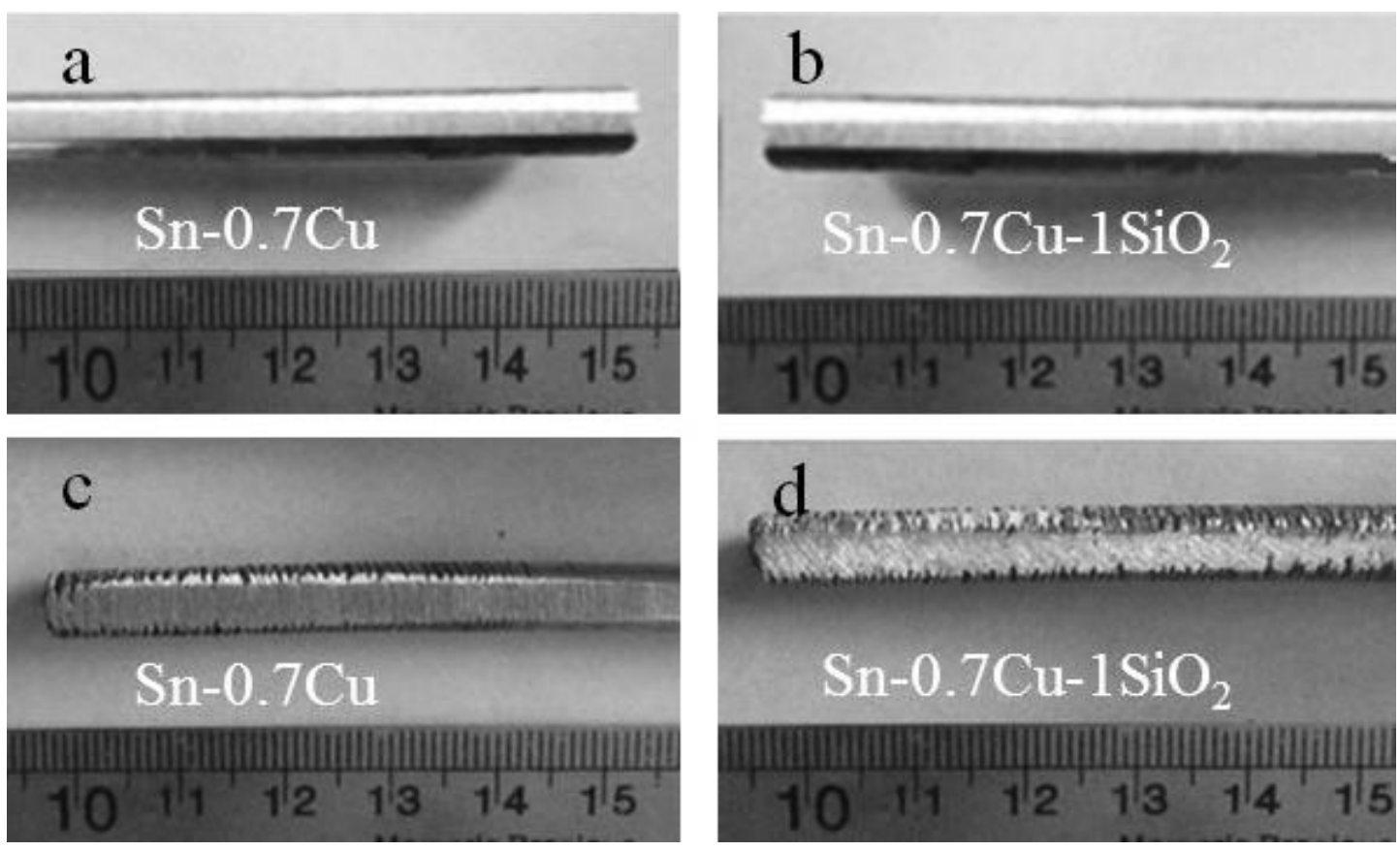

Figure 6. a) Rod of $\mathrm{Sn}-0.7 \mathrm{Cu}$ sample extruded at room temperature, b) rod of $\mathrm{Sn}-0.7 \mathrm{Cu}$ reinforced with $1 \mathrm{wt} \%$ nanosilica extruded at room temperature, c) rod of $\mathrm{Sn}-0.7 \mathrm{Cu}$ sample extruded at $200^{\circ} \mathrm{C}$ and d) rod of $\mathrm{Sn}-0.7 \mathrm{Cu}$ reinforced with $1 \mathrm{wt} \%$ nanosilica extruded at $200^{\circ} \mathrm{C}$.

\subsection{Microstructural investigation}

Microstructural studies were performed to investigate the effects of ceramic nanoparticles on the microstructure of the $\mathrm{Sn}-0.7 \mathrm{Cu}$ matrix. Fig. 7 indicates optical micrograph of as-polished (nonetched) monolithic and $2 \mathrm{wt} \%$ nanoparticle reinforced composite. The monolithic sample is integrated, has a defect-free appearance while in the composite sample some dark and grain boundary-like areas are visible. These looks to be defects like pores and agglomerates of reinforcement particles between the matrix powder particles which prevent complete metal particles joining during sintering. 

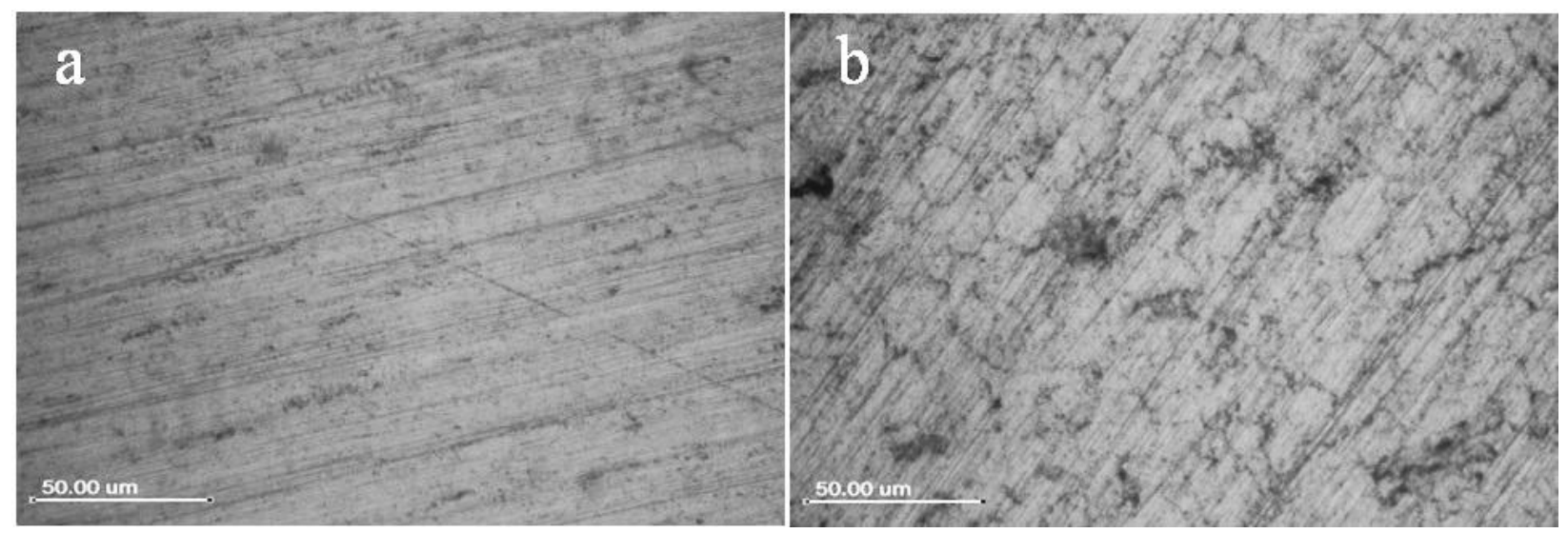

Figure 7. Optical micrograph of as-polished a) $\mathrm{Sn}-0.7 \mathrm{Cu}$ and b) $\mathrm{Sn}-0.7 \mathrm{Cu}-2 \mathrm{wt} \% \mathrm{SiO}$ (np) $\operatorname{samples}$.

Fig. 8 is scanning electron microscopy of the monolithic and $2 \mathrm{wt} . \%$ nanoSiO 2 reinforced samples. In both samples grain boundaries and pores are visible. The monolithic sample is of high integrity and has the least pores. In the composite sample, there are more pores and the boundary between grains is thicker because of agglomeration of nanoparticles. In addition the average grain size was reduced from about 14 micrometers for the monolithic sample to about 6 micrometers for the sample with $2 \mathrm{wt} . \%$ nanoparticles. The average grain size is smaller in the latter which is believed to be due to grain growth prevention by the nanoparticles. 

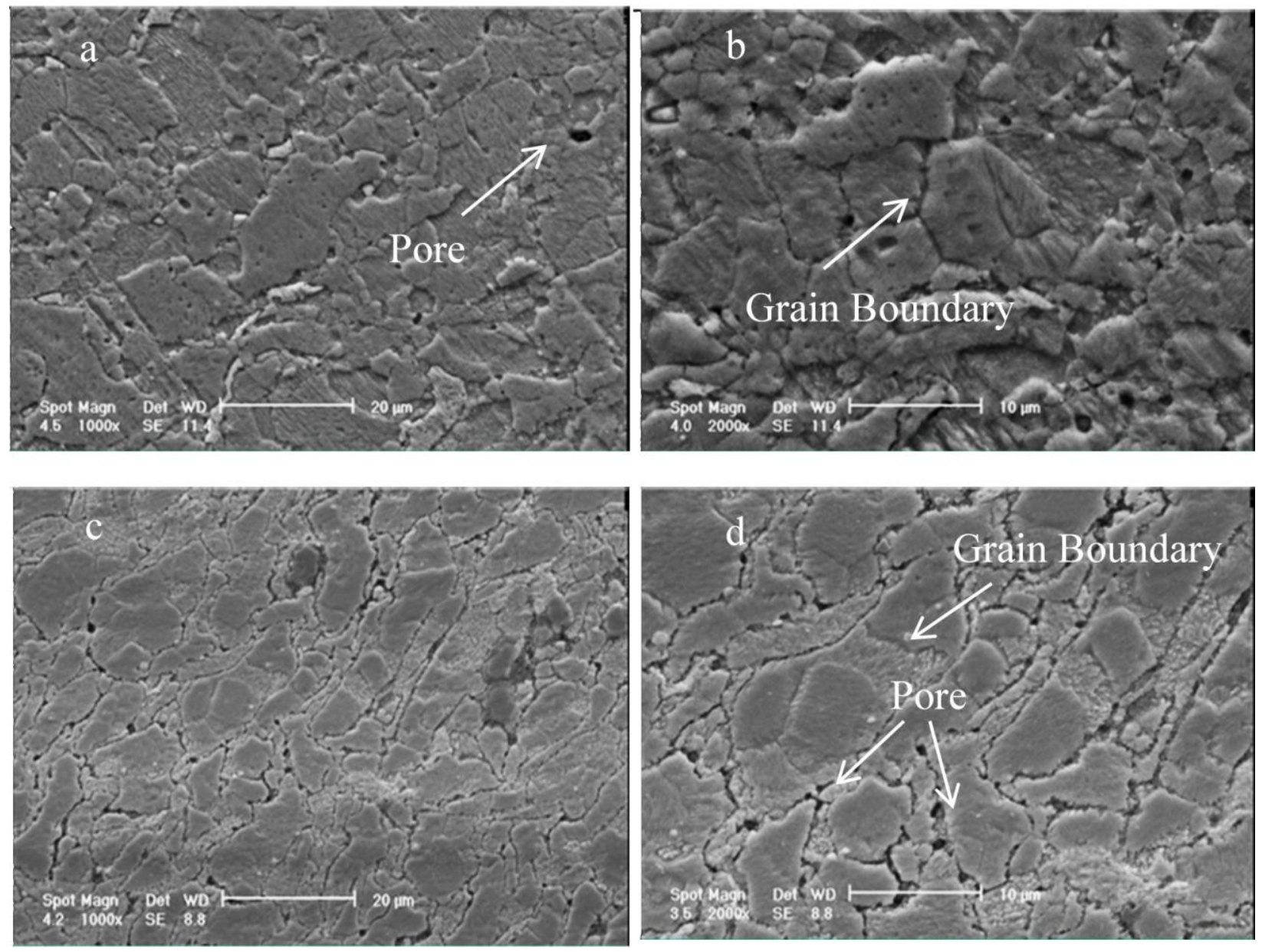

Figure 8. SEM micrographs of Sn-0.7Cu samples, a, b) monolithic and c, d) containing 2wt.\% nanoSiO${ }_{2}$.

It is concluded from abovementioned microstructural studies that in composite samples, agglomeration of nanoparticles on the surface and between metal powder particles prevents complete contact of metallic surfaces in compression stage and consequently full consolidation in sintering stage, however the extrusion process results in a proper lead-free solder. In order to confirm these findings, SEM micrographs of as polished (not etched) $2 \%$ nanoparticle reinforced composite sample were prepared at higher magnification. As can be seen in Figs. 9a and b, the dark areas are agglomerate of ceramic particles which looks like pores at lower magnifications. Fig. 9c and $\mathrm{d}$ shows image of the dark areas at higher magnification. It reveals that there are more pores around the agglomerates. 

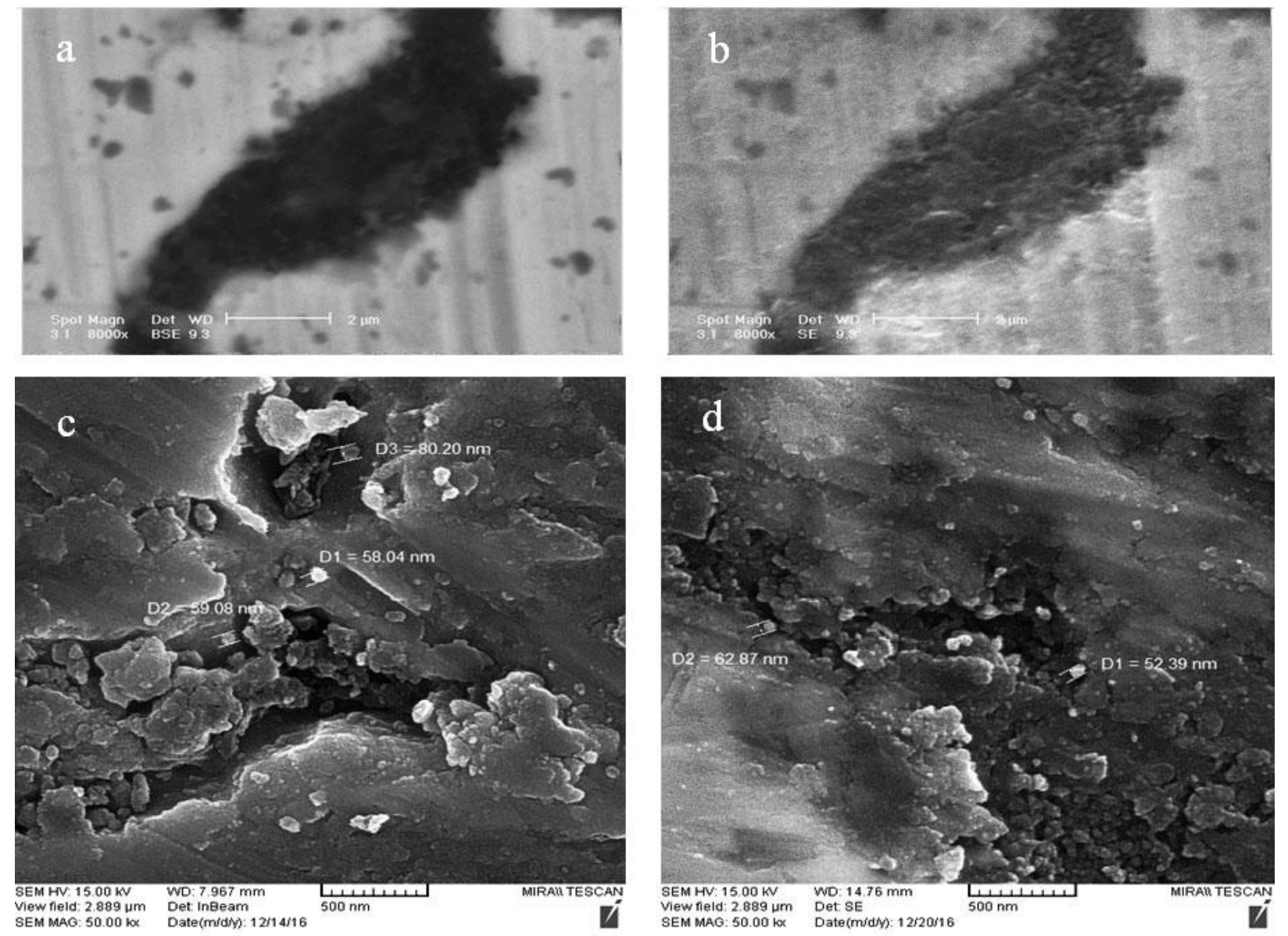

Figure 9. Micrographs of as polished (not etched) $\mathrm{Sn}-0.7 \mathrm{Cu}-2 \mathrm{wt} \% \mathrm{SiO}_{2}$ samples: a) $\mathrm{SEM}-\mathrm{BSE}$,

b) SEM-SE., c) and d) FESEM at different magnifications.

To identify the chemical composition of the phases observed, energy dispersive spectroscopy (EDS) was performed (Fig. 10). Analysis of the dark areas (Figs. 10a and 10b) reveals presence of $\mathrm{Sn}, \mathrm{Si}$ and $\mathrm{O}$. The $\mathrm{Sn}$ is from the matrix, while $\mathrm{Si}$ and $\mathrm{O}$ are from nanosilica agglomerates in grain boundaries. There is no concern about reaction between tin and nanosilica, because this reaction is thermodynamically impossible [23] at any temperature, and consequently nanosilica is stable in the matrix. Fig. 10c is EDS of the matrix which indicates only Sn. EDS analysis at higher magnification (Fig. 11), which is less affected by matrix composition, confirms that the dark areas are rich in $\mathrm{Si}$ and $\mathrm{O}$ and is in agreement with Figs. 10a and 10b. 

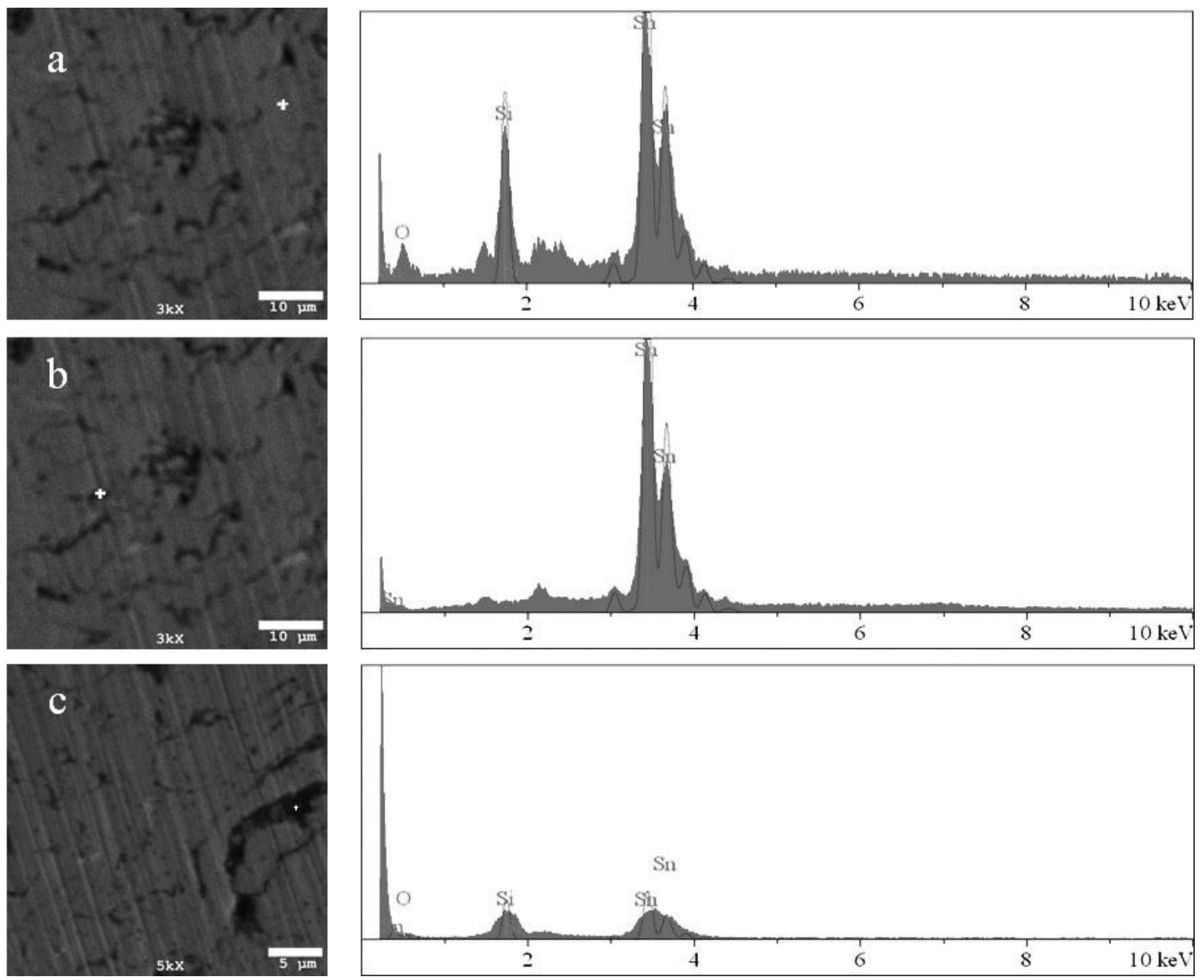

Figure 10. Energy dispersive spectrometry of a) and b) dark areas and c) matrix.
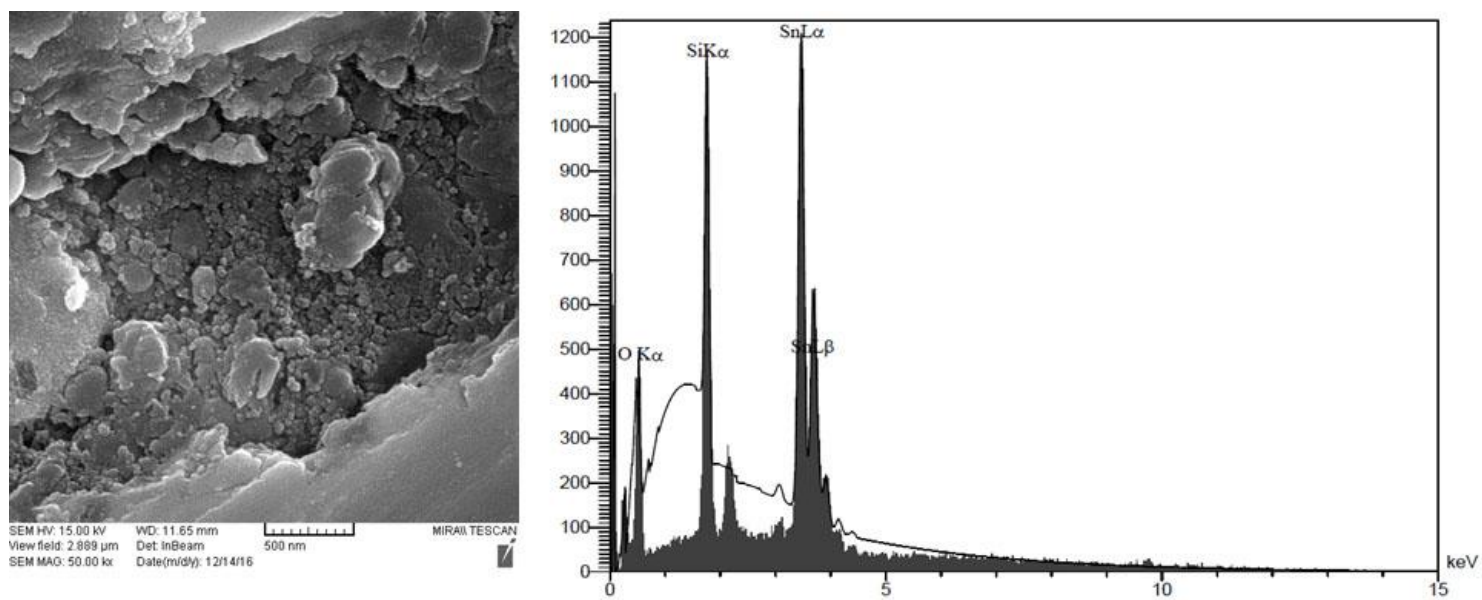

Figure 11. Energy dispersive spectrometry of dark areas at higher magnification 
Nanosilica has a density less than $3 \mathrm{~g} / \mathrm{cm}^{3}$ [24], while density of tin is more than $7 \mathrm{~g} / \mathrm{cm}^{3}$ [25]. Therefore, the volume fraction of nanosilica is higher than its weight fraction. For instance in $2 \mathrm{wt} . \%$ nano-silica reinforced composite, volume percent of the nano-silica is $6.3 \%$. Furthermore, because of the very fine size of nano-silica particles used in this study compared to those used by other researchers in this matrix $[9,16,26]$, even a small content of amorphous nanosilica can effectively change the lead free solder properties.

\subsection{Mechanical properties}

Fig. 12 shows tensile test curves of the samples containing 0 to $2 \mathrm{wt}$.\% nanoparticles. As can be seen, by adding up to $1.5 \mathrm{wt} \%$ percent nanoparticles, yield and tensile strengths were increased, elongation was changed negligibly, while elastic modulus was decrease. The increase in strength can be due to addition of ceramic particles which are harder than the matrix. The reason of almost no change in elongation is not exactly clear and needs more investigation. Usually, strength increase in metal matrix composites is at the cost of elongation decrease. However, similar results was also reported by Senemar [27], when employed amorphous nanosilica for reinforcing aluminum matrix. It can be postulated that grain refinement of the matrix by addition of nanosilica (Fig. 8) may have counterbalanced the negative effects of porosity and hard particles on elongation. Elastic modulus seems to be decreased because of increased porosity in the matrix which can adversely affect modulus, however the strength is still higher than monolithic sample. At $2 \mathrm{wt} \%$ added reinforcement sample the strength was decreased compared to $1.5 \mathrm{wt} . \%$, because increased porosity presumably dominated. 


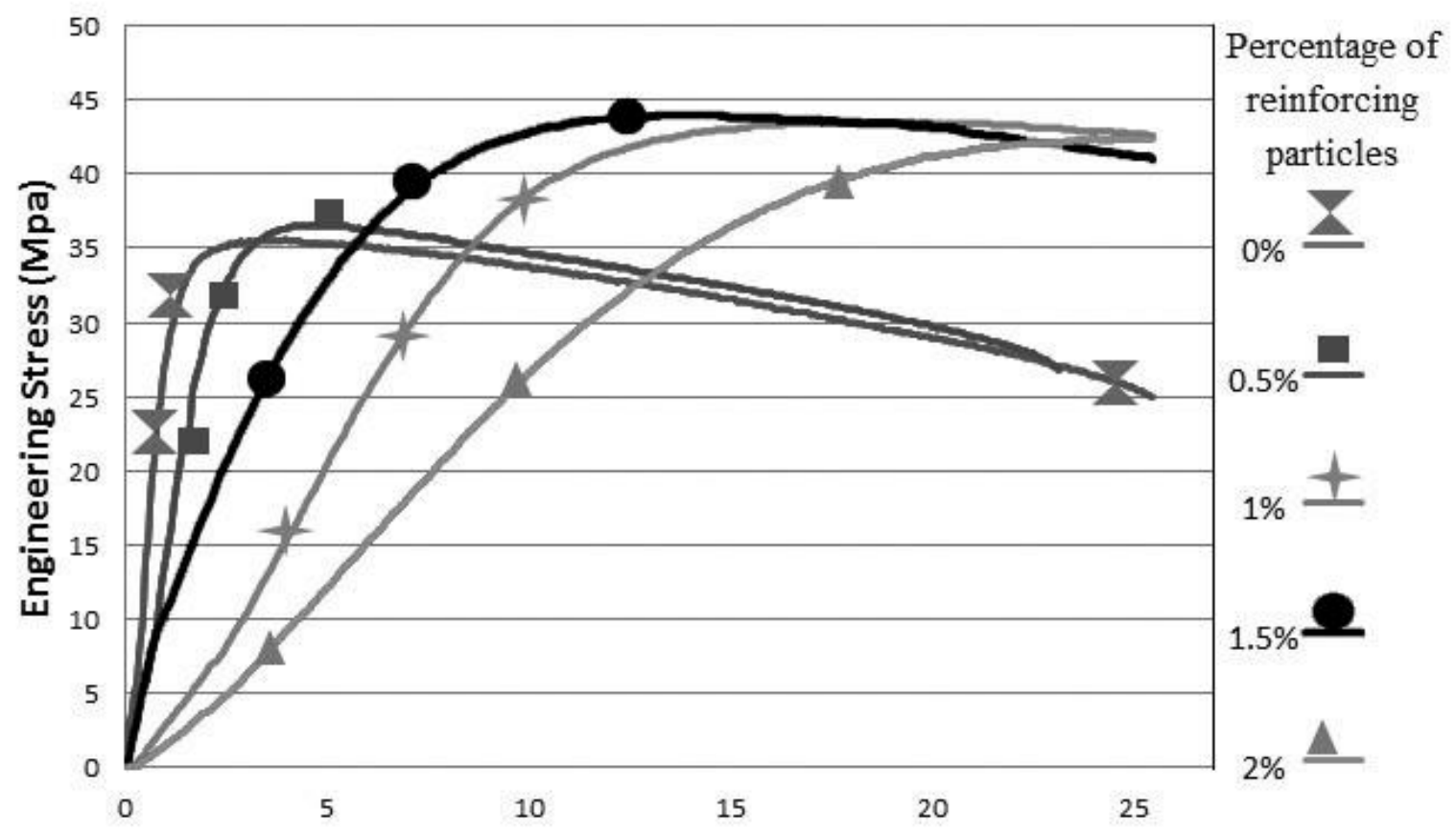

Engineering Strain\%

Figure 12. Tensile test (strain-stress) curves of samples containing 0-2 wt.\% reinforcements.

Mechanical properties of monolithic and composite samples were also measured by microhardness and compression tests. Table 1 is a summary of the obtained properties. As can be seen, by adding nanoparticles to the $\mathrm{Sn}-0.7 \mathrm{Cu}$ matrix, mechanical properties were increased. The highest mechanical properties were achieved at $1.5 \mathrm{wt} . \%$ nanoSiO${ }_{2}$ addition, where yield, tensile and compressive strengths were increased by 23\%, 27\% and 38\%, respectively. Microhardness was increased around $135 \%$ for this sample, however the increase in microhardness was a bit higher for $2 \mathrm{wt} \%$ nanoSiO 2 added sample. 
Table 1. Mechanical properties of $\mathrm{Sn}-0.7 \mathrm{Cu}$ monolithic and composite samples

\begin{tabular}{|c|c|c|c|c|}
\hline $\begin{array}{c}\text { Nano } \mathrm{SiO}_{2} \\
\text { content }(\%)\end{array}$ & $\begin{array}{c}\text { Microhardness } \\
(\mathrm{HV})\end{array}$ & $\begin{array}{c}\text { Yield strength } \\
(\mathrm{MPa})\end{array}$ & $\begin{array}{c}\text { Ultimate tensile } \\
\text { strength (MPa) }\end{array}$ & $\begin{array}{c}\text { Compressive } \\
\text { strength (MPa) }\end{array}$ \\
\hline 0 & $5.5 \pm 0.7$ & $31.8 \pm 0.8$ & $34.2 \pm 1.3$ & $33.5 \pm 1.5$ \\
\hline 0.5 & $10.4 \pm 0.5$ & $34.2 \pm 0.2$ & $36.5 \pm 0.1$ & $37.7 \pm 1.3$ \\
\hline 1 & $11.8 \pm 0.7$ & $38.2 \pm 0.3$ & $42.43 \pm 1.1$ & $45.5 \pm 0.5$ \\
\hline 1.5 & $13 \pm 0.6$ & $39.2 \pm 0.1$ & $43.4 \pm 5$ & $46.5 \pm 0.6$ \\
\hline 2 & $14.3 \pm 0.3$ & $37.9 \pm 0.6$ & $42.4 \pm 0.4$ & $41.7 \pm 0.56$ \\
\hline
\end{tabular}

Mechanical properties increase could be due to increase in the number of ceramic particles resisting against plastic deformation. In addition, the coefficient of thermal expansion (CTE) difference between the matrix and particulate reinforcements (CET for SC solder= $17.37 \times 10^{-6} /{ }^{\circ} \mathrm{C}$ [12] and for $\mathrm{SiO}_{2}=0.55 \times 10^{-6} /{ }^{\circ} \mathrm{C}$ [24]) increases dislocation density and consequently mechanical properties $[9,28]$.

Increased mechanical properties could be due to the Orowan strengthening mechanism, increased density of dislocations due to thermal mismatch between matrix and particles, generation of dislocations due to difference in the yield strength and elastic modulus of matrix and particles and load transfer to the reinforcement particles. Therefore, strength of the composites can be expressed as [9]:

$\Delta \sigma=\sigma_{\text {Orowan }}+\sigma_{\mathrm{CTE}}+\sigma_{\mathrm{GND}}+\sigma_{\mathrm{Load}}$

The greatest increase in strength is because of the Orowan strengthening and difference in CTE of the particles and the matrix. Increase of strength by Orowan strengthening mechanisms can be calculated by following formula [29].

$\Delta \sigma$ orowan $=\frac{0.13 \mathrm{G}_{\mathrm{m}} \mathrm{b}}{i} \ln \frac{r}{b}$

where $\mathrm{G}_{\mathrm{m}}$ is the shear modulus of matrix (shear modulus of tin $=18 \mathrm{GPa}[30]$ ), $\mathrm{b}$ is Burgers vector of matrix $\left(b_{\mathrm{sn}}=0.317 \mathrm{~nm}[31]\right), r$ is the average radius of nanoparticles and the average distance between nanoparticles $(\lambda)$ is [29]:

$\lambda \approx d_{p}\left[\left(\frac{1}{2 V_{p}}\right)^{\frac{1}{x}}-1\right]$

where $V_{p}$ is the volume fraction of nanoparticles and $d_{p}$ is the particle size. 
Increase of strength by difference in CTEs can be calculated as [32].

$\Delta \sigma_{C T E}=\sqrt{3} \beta G_{m} b \sqrt{\frac{12 V_{p} \Delta \alpha \Delta T}{\left(1-V_{p}\right) b d_{p}}}$

Where $\beta$ is $1.25, \Delta \alpha$ is the difference between the CTEs of the particle and matrix and $\Delta \mathrm{T}$ is difference between process and testing temperatures.

Since in this study, after sintering, extrusion was performed at room temperature, $\Delta \mathrm{T}$ is zero. Consequently $\Delta \sigma_{\mathrm{CTE}}$ is also zero, whereas $\sigma_{\text {Orowan }}$ for $1.5 \%$ nanosilica content is $82 \mathrm{MPa}$. This is much higher than the experimental values obtained. It seems to be because of particles agglomeration on surface and between metal powder particles which results in non-uniform distribution of ceramic particles and pore formation in the composites (Figs. 8 and 9).

Addition of micro and nanoparticles prevents coarsening of microstructure of lead-free solder, contributes to formation of intermetallic compounds such as $\mathrm{Cu}_{6} \mathrm{Sn}_{5}$ and causes hardening of the material. These particles also affect wettability, creep resistance and hardness of the solder [14]. However, addition of nanoparticles has some adverse effects, including increased porosity in liquid state processes. On the other hand, it has been reported that in powder metallurgy methods addition of nanoparticles should not exceed a certain limit, otherwise the properties will be reduced, as in $2 \%$ nanosilica reinforced sample in this study, because increased number of nanoparticles could increase the number of micropores. Microscopic pores determine the strength, because they are potential zones for crack initiation which finally leads to failure [28, $33,34]$.

According to the microstructural observations in this study, nanoparticles content above a certain limit, increases number of particles in the surface and between powder particles which prevents complete connection of powder particles during compression and joining during sintering. It means that strengthening effect of nanoparticles is less than their adverse effect above $1.5 \%$ nanosilica in this research and therefore mechanical properties fall when nanosilica content is $2 \%$.

As mentioned earlier, there are few researches on reinforcing $\mathrm{Sn}-\mathrm{Cu}$ matrix with ceramic nanoparticles. Table 2 shows mechanical properties of conventional $\mathrm{Sn}-\mathrm{Pb}$ solder and $\mathrm{Sn}-0.7 \mathrm{Cu}$ matrix nanocomposites reinforced with different nanoparticles. It is evident that amorphous 
nanosilica can be more effective than other particles already used, on improving the mechanical properties of $\mathrm{Sn}-0.7 \mathrm{Cu}$ nanocomposite.

Table 2. Mechanical properties of conventional $\mathrm{Sn}-\mathrm{Pb}$ solder and $\mathrm{Sn}-0.7 \mathrm{Cu}$ matrix nanocomposite

\begin{tabular}{|c|c|c|c|c|c|c|c|}
\hline Researcher & Method & Material & Microhardness & $\begin{array}{c}\text { Tensile } \\
\text { strength } \\
(\mathrm{MPa})\end{array}$ & $\begin{array}{c}\text { Tensile } \\
\text { strength } \\
\text { increase } \\
(\%)\end{array}$ & $\begin{array}{c}\text { Yield } \\
\text { strength } \\
(\mathrm{MPa})\end{array}$ & $\begin{array}{c}\text { Yield } \\
\text { strength } \\
\text { increase } \\
(\%)\end{array}$ \\
\hline $\begin{array}{l}\text { Qualitek, } \\
\text { USA [35] }\end{array}$ & - & $\mathrm{Sn}-37 \mathrm{~Pb}$ & $27(\mathrm{HB})$ & 31 & - & 48 & - \\
\hline \multirow[t]{2}{*}{ Tsao [12] } & \multirow[t]{2}{*}{ Liquid state } & $\mathrm{Sn}-\mathrm{Cu}-0.5 \mathrm{Ti}_{2} \mathrm{O}$ & - & $\begin{array}{c}42.08 \pm 3.1 \\
2\end{array}$ & \multirow[t]{2}{*}{$10 \%$} & $\begin{array}{c}39.02 \pm 1.6 \\
5\end{array}$ & \multirow[t]{2}{*}{$10.7 \%$} \\
\hline & & $\mathrm{Sn}-\mathrm{Cu}-1 \mathrm{Ti}_{2} \mathrm{O}$ & - & $46.3 \pm 1.68$ & & $43.2 \pm 2.8$ & \\
\hline \multirow{2}{*}{ Zhong [9] } & \multirow{2}{*}{$\begin{array}{l}\text { Powder } \\
\text { metallurgy } \\
\text { method }\end{array}$} & $\begin{array}{c}\mathrm{Sn}-\mathrm{Cu}- \\
0.5 \mathrm{Al}_{2} \mathrm{O}_{3}\end{array}$ & $9.3 \pm 0.2(\mathrm{HV})$ & $32 \pm 3$ & \multirow[t]{2}{*}{$12.5 \%$} & $29 \pm 4$ & \multirow[t]{2}{*}{$10.3 \%$} \\
\hline & & $\mathrm{Sn}-\mathrm{Cu}-1 \mathrm{Al}_{2} \mathrm{O}_{3}$ & $9.9 \pm 0.3(\mathrm{HV})$ & $36 \pm 1$ & & $32 \pm 2$ & \\
\hline \multirow{2}{*}{$\begin{array}{l}\text { Present } \\
\text { research }\end{array}$} & \multirow{2}{*}{$\begin{array}{l}\text { Powder } \\
\text { metallurgy } \\
\text { method }\end{array}$} & $\mathrm{Sn}-\mathrm{Cu}-0.5 \mathrm{SiO}_{2}$ & $5.5 \pm 0.7(\mathrm{HV})$ & $36.5 \pm 0.1$ & \multirow{2}{*}{$16 \%$} & $34.2 \pm 0.2$ & \multirow[t]{2}{*}{$12 \%$} \\
\hline & & $\mathrm{Sn}-\mathrm{Cu}-1 \mathrm{SiO}_{2}$ & $11.8 \pm 0.7(\mathrm{HV})$ & $42.4 \pm 1.1$ & & $38.3 \pm 0.4$ & \\
\hline
\end{tabular}

\subsection{Wetting}

Fig. 13 shows a solidified Sn-0.7Cu nanocomposite droplet on a copper substrate. Proper wetting of substrate is important in case of solders. Substrate is usually copper which can react with solder during solidification and form intermetallic compounds. This also can affect triple point equilibrium as defined by equation 5 [14].

$\cos \theta=\frac{7_{g}-7_{15}}{7_{g}}$

where $\theta$ is the wetting angle, $\gamma_{\mathrm{gs}}$ is the surface tension between air and the substrate, $\gamma_{1 \mathrm{~s}}$ is the surface tension between the molten droplet and the substrate and $\gamma_{\mathrm{gl}}$ is the surface tension between the molten droplet and air. A low wetting angle means good wettability of substrate by the droplet. 
When nanoparticles are added to a lead-free solder, surface energy of the molten solder and reactions between substrate and solder are affected. Also if nanoparticles segregate in triple point, they can affect balance of forces and reduce energy of the triple point $[14,33]$.

Fig. 14 shows the wetting angle of $\mathrm{Sn}-0.7 \mathrm{Cu}$ nanocomposites at different nanosilica content of the solder measured by image analysis of photos like Fig. 13. It is evident that by increasing the nanoparticles content, wetting angle decreases and consequently a better joint between the solder and the substrate is expected. The decrease of wetting angle is around 30\% for addition of $1.5 \%$ nanosilica.

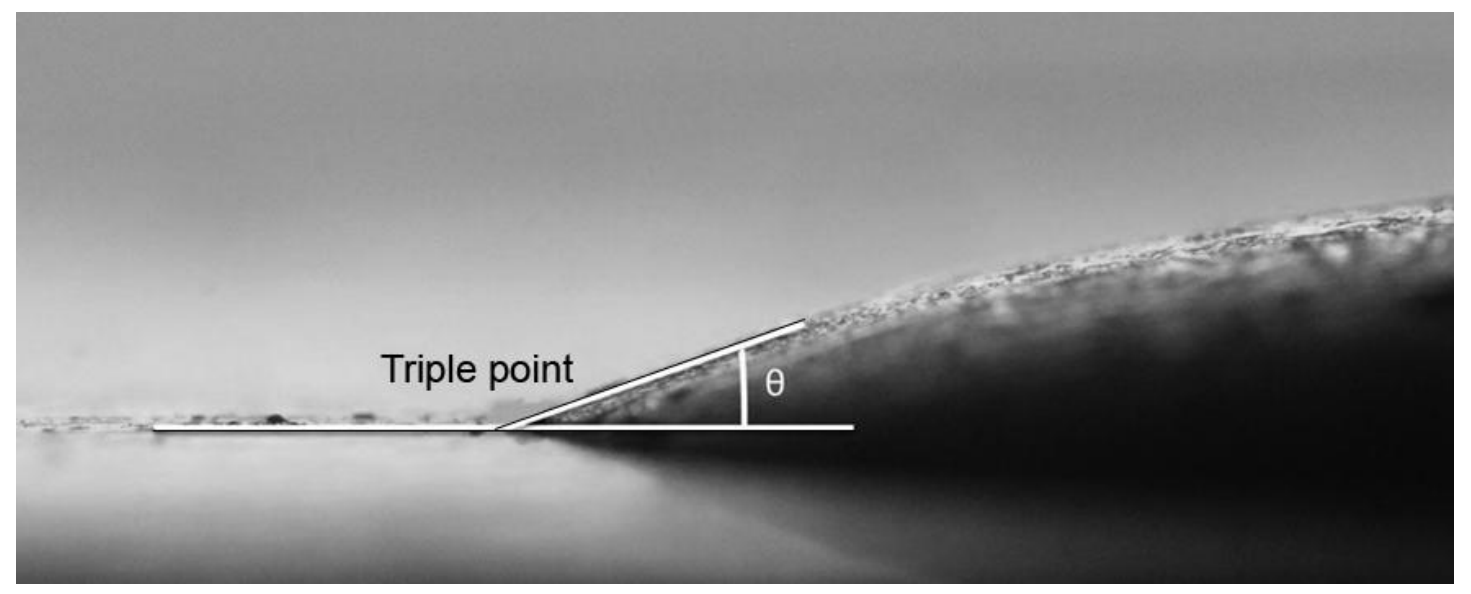

Figure 13. A solidified droplet of lead-free composite solder on the copper substrate. 


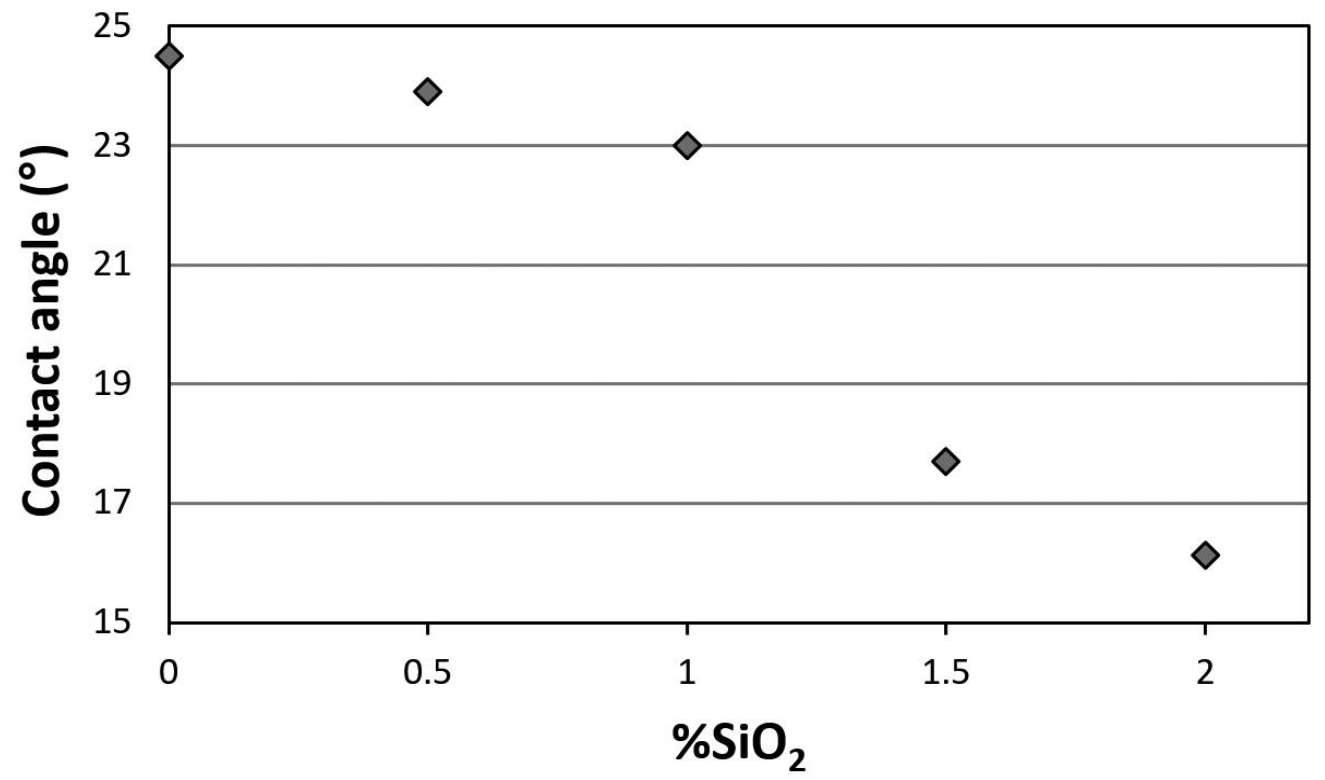

Figure 14. Wetting angle of Su-0.7Cu lead-free solders reinforced with different percent of nanosilica.

\section{Conclusions}

1- $\quad \mathrm{Sn}-\mathrm{Cu}-\mathrm{SiO}_{2}$ lead free nanocomposite solder could be successfully synthesized by powder metallurgy and extrusion.

2- Amorphous nanosilica could effectively improve mechanical properties and wetting angle of $\mathrm{Sn}-0.7 \mathrm{Cu}$ lead free solder. The improvement was comparable to those of other nanoparticles in previous researches.

3- $\quad$ The appropriate temperature for extrusion of the lead free nanocomposite solder was found to be room temperature.

4- $\quad$ Addition of $1.5 \%$ nanoparticles resulted in the optimum mechanical properties obtained. It increased tensile and compressive strength of the solder by $27 \%$ and $41 \%$, respectively. Microhardness of this sample increased by around $135 \%$.

5- $\quad$ Addition of $2 \%$ nanoparticles caused a drop in the mechanical properties such as tensile and compressive strength. Microstructural observations suggested that the decrease in the mechanical properties occurred due to the increased porosity and agglomeration of nanoparticles. 
6- Wetting angle of copper substrate by the nanocomposite solder decreased around $30 \%$ for the optimum sample.

\section{Acknowledgement}

This research has been conducted at Isfahan University of Technology and supported by Iran National Science Foundation (INSF) under contract number 94-S-44221.

\section{References}

[1] H. Ma , J. C. Suhling, "A review of mechanical properties of lead-free solders for electronic packaging" , Journal of Materials science, vol. 44, pp. 1141-1158, 2009.

[2] F. Wang, X. Ma, Y. Qian, "Improvement of microstructure and interface structure of eutectic Sn$0.7 \mathrm{Cu}$ solder with small amount of Zn addition" , Scripta materialia, vol. 53, pp. 699-702, 2005.

[3] K. Prabhu, "Reactive wetting, evolution of interfacial and bulk IMCs and their effect on mechanical properties of eutectic $\mathrm{Sn}-\mathrm{Cu}$ solder alloy", Advances in colloid and interface science, vol. 166, pp. 87-118, 2011.

[4] J. Glazer, "Microstructure and mechanical properties of $\mathrm{Pb}$-free solder alloys for low-cost electronic assembly: a review", Electronic materials, vol. 23, pp. 693-700, 1994.

[5] I. E. Anderson, "Development of $\mathrm{Sn}-\mathrm{Ag}-\mathrm{Cu}$ and $\mathrm{Sn}-\mathrm{Ag}-\mathrm{Cu}-\mathrm{X}$ alloys for $\mathrm{Pb}$-free electronic solder applications", Journal of Materials science: materials in electronics, vol. 18, pp. 55-76, 2007.

[6] M. Islam, Y. Chan, M. Rizvi, W. Jillek, "Investigations of interfacial reactions of Sn-Zn based and $\mathrm{Sn}-\mathrm{Ag}-\mathrm{Cu}$ lead-free solder alloys as replacement for $\mathrm{Sn}-\mathrm{Pb}$ solder", Alloys and compounds, vol. 400, pp. 136-144, 2005.

[7] H. R. Kotadia, P. D. Howes, S. H. Mannan, "A review: on the development of low melting temperature Pb-free solders", Microelectronics reliability, vol. 54, pp. 1253-1273, 2014.

[8] X. Zhong, M. Gupta, "Effect of type of reinforcement at nanolength scale on the tensile properties of Sn-0.7 Cu solder alloy", In electronics packaging technology conference, 2008. EPTC 2008. 10th, 2008, pp. 669-674.

[9] X. Zhong, M. Gupta, "Development of lead-free Sn-0.7 Cu/Al2O3 nanocomposite solders with superior strength", Physics D: applied physics, vol. 41, p. 095403, 2008.

[10] S. Xu, A. H. Habib, A. D. Pickel, M. E. McHenry, "Magnetic nanoparticle-based solder composites for electronic packaging applications", Progress in materials science, vol. 67, pp. 95$160,2015$.

[11] J. Bath, Lead-free soldering: Springer Science \& Business Media, 2007. 
[12] L. Tsao, C. Huang, C. Chung, R. Chen, "Influence of $\mathrm{TiO}_{2}$ nanoparticles addition on the microstructural and mechanical properties of $\mathrm{Sn}-0.7 \mathrm{Cu}$ nano-composite solder", Materials science and engineering: A, vol. 545, pp. 194-200, 2012.

[13] J. Shen and Y. C. Chan, "Research advances in nano-composite solders", Microelectronics reliability, vol. 49, pp. 223-234, 2009.

[14] L. Zhang, K. Tu, "Structure and properties of lead-free solders bearing micro and nano particles", Materials science and engineering: R: Reports, vol. 82, pp. 1-32, 2014.

[15] M. Gupta , W. Wong, "Enhancing overall mechanical performance of metallic materials using two-directional microwave assisted rapid sintering," Scripta materialia, vol. 52, pp. 479-483, 2005.

[16] S. Nai, J. Kuma, M. Alam, X. Zhong, P. Babaghorbani, M. Gupta, "Using microwave-assisted powder metallurgy route and nano-size reinforcements to develop high-strength solder composites", Journal of materials engineering and performance, vol. 19, pp. 335-341, 2010.

[17] M. Senemar, A. Maleki, B. Niroumand, A. Allafchian", A novel and facile method for silica nanoparticles synthesis from high temperature vulcanization (HTV) silicon," Metallurgical and materials engineering, vol. 22, pp. 1-8, 2016.

[18] http://metsofts.ir/microstructure-image-processing/ Last visited on 2.12.2016

[19] ASTM Standard, "E384, Standard test method for microindentation hardness of materials", Annual Book of ASTM Standards, West Conshohocken, PA: ASTM International, 2000.

[20] ASTM Standard, "Standard Test Methods of Compression Testing of Metallic Materials at Room Temperature", Annual Book of ASTM Standards, ASTM, West Conshohocken, PA, pp. 98-105, 1990.

[21] ASTM Standard, "Standard test methods for tension testing of metallic materials", Annual book of ASTM standards. ASTM, 2001.

[22] C. Nikhilesh , K. K. Chawla, "Metal matrix composites", ed: Springer: New York, NY, USA, 2006.

[23] H. J. T. Ellingham, "Reducibility of oxides and sulfides in metallurgical processes", J soc. chem. ind., vol. 63, pp. 125-133, 1944.

[24] D. R. Lide, CRC Handbook of Chemistry and Physics: A Ready-reference Book of Chemical and Physical Data: 1993-1994: CRC press, 1993.

[25] A. M. James, M. P. Lord, Macmillan's chemical and physical data: Macmillan, 1992.

[26] M. Salleh, M. A. Anuar, M. H. Hazizi, Z. A. Ahmad, K. Hussin, K. R. Ahmad, "Wettability, electrical and mechanical properties of $99.3 \mathrm{Sn}-0.7 \mathrm{Cu} / \mathrm{Si}_{3} \mathrm{~N}_{4}$ novel lead-free nanocomposite solder", in Advanced Materials Research, 2011, pp. 106-111.

[27] M. Senemar, "Synthesis and characterization of in-situ aluminum matrix composite reinforced with particles silicon and oxygen through pyrolysis of high temperature vulcanization (HTV) silicone" , M.Eng. thesis, Materials Engineering. Dept., Isfahan University Technology, Iran, 2016.

[28] P. Babaghorbani, "Development of Lead-Free Nanocomposite Solders for Electronic Packaging", M.Eng. thesis, Mechanical Engineering. Dept., National University of Singapore, Singapore, 2008.

[29] Z. Zhang, D. Chen, "Consideration of Orowan strengthening effect in particulate-reinforced metal matrix nanocomposites: A model for predicting their yield strength", Scripta materialia, vol. 54, pp. 1321-1326, 2006.

[30] http://periodictable.com/Properties/A/ShearModulus.an.html.

[31] R. Sidhu, X. Deng, N. Chawla, "Microstructure characterization and creep behavior of Pb-free Sn-rich solder alloys: Part II. Creep behavior of bulk solder and solder/copper joints", Metallurgical and Materials Transactions A, vol. 39, pp. 349-362, 2008.

[32] M. Habibnejad-Korayem, R. Mahmudi, W. Poole, "Enhanced properties of Mg-based nanocomposites reinforced with $\mathrm{Al}_{2} \mathrm{O}_{3}$ nano-particles", Materials Science and Engineering: A, vol. 519, pp. 198-203, 2009. 
[33] S. Nai, J. Wei, M. Gupta, "Improving the performance of lead-free solder reinforced with multiwalled carbon nanotubes," Materials Science and Engineering: A, vol. 423, pp. 166-169, 2006.

[34] S. Nai, J. Wei, M. Gupta, "Influence of ceramic reinforcements on the wettability and mechanical properties of novel lead-free solder composites," Thin solid films, vol. 504, pp. 401-404, 2006.

[35] https://www.qualitek.com/, Last visited on 4.10.2016 